Historia y comunicación social

ISSN-e 1988-3056

https://dx.doi.org/10.5209/hics.66299

\title{
Posverdad y desinformación en la era de los nuevos formatos
}

\author{
Belén Mainer Blanco ${ }^{1}$; Humberto Martínez-Fresneda Osorio ${ }^{2}$
}

Recibido: 26 de marzo de 2019 / Aceptado: 25 de septiembre de 2019.

Resumen. Este artículo es el resultado de una investigación realizada en la Facultad de Comunicación de la Universidad Francisco de Vitoria de Madrid entre alumnos del Grado en Periodismo y el Grado en Creación y Narración de Videojuegos, a quienes se les expuso un hecho informativo en formato audiovisual e interactivo. Pese a que las nuevas generaciones valoran positivamente las aportaciones de cada uno de los formatos existen ciertas dificultades en aceptar los nuevos lenguajes como válidos para transmitir el mensaje, lo que puede llegar, si no se realizan las acciones formativas necesarias, a dañar la verdad en el relato informativo.

Palabras clave: posverdad; medios de comunicación; nuevos formatos; Periodismo; Videojuegos.

\section{[en] Post-truth and disinformation in the new formats Era}

\begin{abstract}
This article is the result of an investigation carried out in the Faculty of Communication at the Francisco de Vitoria University in Madrid among Students of Journalism's Degree and Videogame's Degree. The Students were exposed to a feature in two formats: video and interactive. Young people value the contributions of the new formats, but there are certain difficulties to understand them as solid reliable sources of information. For that it is necessary to train actions to protect the truth in the informative story.
\end{abstract}

Keywords: post-truth; new media; new formats; Journalism; Videogames.

Summary: 1. Introducción; 2. Estado de la cuestión; 3. Metodología; 3.1. Muestra; 3.2. Medidas; 4. Resultados; 5. Conclusiones; 6. Referencias bibliográficas.

Cómo citar: Mainer Blanco, B.; Martínez-Fresneda Osorio, H. (2019). Posverdad y desinformación en la era de los nuevos formatos, en Historia y comunicación social 24 (2), 547-559.

\section{Introducción}

El concepto de manipulación ha sido tratado por numerosos autores. Alguno de ellos, (López-Quintas, 2001) pone el acento en el reduccionismo al que ha sido sometido

\footnotetext{
1 Universidad Francisco de Vitoria. b.mainer@ufv.es

2 Universidad Francisco de Vitoria. h.fresneda@ufv.es
} 
el hombre, pasando de sujeto a objeto para hacerlo más manipulable y anularle la capacidad de iniciativa. En esta línea, otros autores (Blázquez, 2000) afirman que "manipular es transformar algo, cambiar algo, hacer que algo pase de un ser a otro alterando su estado primero, su estado inicial". Igualmente, se afirma que "toda comunicación ha de ajustarse a la ley primordial de la verdad, sinceridad y honradez" (Vázquez, 1990).

Esto, llevado al campo de los medios de comunicación, supone que los que los ciudadanos son adoctrinados de manera constante, de un modo invisible y clandestino, pero tremendamente eficaz (Gutiérrez, 1996).

En ese sentido, "todo parece verdadero y falso a la vez. Nada parece importante, y esto desarrolla la indiferencia y estimula el escepticismo" (Ramonet, 1998). En la misma línea, manipular "equivale a intervenir deliberadamente en los datos de una noticia por parte del emisor; a trastocar sutilmente esos datos de modo que, sin anularlos del todo, den a la noticia un sentido distinto del original de acuerdo con unos intereses preconcebidos por parte del emisor, de tal forma que el receptor no pueda apercibirse de esa intervención sin recurrir a otras fuentes de información" (Blázquez, 2000).

El concepto de verdad informativa se ve cuestionado desde el momento en que se plantea cómo es la comunicación de los medios de comunicación, una comunicación que debe tener un emisor y un receptor que intercambien mensajes en igualdad de condiciones a través de un canal eficaz para superar la distancia entre ellos (Gutiérrez, 1996).

Por eso, el concepto de verdad es un campo de debate constante para los periodistas y comunicadores. Algunos estudios concluyen que "aunque el concepto de objetividad lleve años de decadencia, cuando se trata de establecer unos criterios profesionales objetivos, como es el caso de la elaboración de un libro de estilo, se recurre inevitablemente a la verdad del hecho informativo". Los libros de estilo de El País, El Mundo y El ABC revelan que todos los periódicos recogen las premisas objetivistas en favor del hecho informativo, pero en ninguno de ellos se halla un concepto explícito del significado de verdad (Muñoz-Torres, 2000).

Buscar la verdad desde la profesión periodística es el reto de los periodistas si quieren construir una sociedad orientada al bien (García-Noblejas, 2000). En este sentido, frente al relativismo, al escepticismo y a la emotividad de la audiencia, debemos apostar por una verdad que se sustente en una información rigurosa. En esta línea, muchos autores, afirman que el periodismo como servicio a la sociedad debe ofrecer una información independiente, veraz, exacta y ecuánime al que todo ciudadano tiene derecho (Kovach; Rosenstiel, 2003).

La verdad informativa es, al mismo tiempo, verdad lógica en la medida en que supone la adecuación de uno o varios entendimientos a la realidad impelida por el proceso informativo. La verdad es la adecuación o conformidad del mensaje comunicacional del emisor a la realidad social contingente. Adecuación que es percibida por el receptor después de haber pasado el mensaje a través de los medios de comunicación social o mass media = verdad informativa o comunicacional (Blázquez, 2002).

La audiencia puede manifestarse escéptica al recibir los mensajes informativos o, incluso, puede estimar que no es posible encontrar algo a lo cual llamarle verdad informativa debido a la excesiva instrumentalización de los medios de comunicación masiva que los monopolios hegemónicos de los mass media han programado a escala mundial. 
Alerta Blázquez de que el concepto de verdad tiende a ser sistemáticamente suplantado en el campo de la información por el de veracidad. Entre otras cosas porque entre el hecho que merece la atención y la plasmación mediática de ese hecho hay un proceso de toma y selección de datos, traslación a un lenguaje escrito o audiovisual y edición de la noticia o del mensaje que supone toda una mediación o, lo que es lo mismo, la fabricación de la realidad mediada (Sánchez-Noriega, 2002).

Ser conscientes de este proceso supone estar advertidos del potencial de influencia que tienen los medios y de la artificialidad de su función mediadora. Además, esto supone saber que inevitablemente los medios manipulan la realidad, en cuanto elaboran sus mensajes a partir de una materia prima, pero también manipulan las conciencias cuando ocultan ese proceso y ofrecen como la realidad misma aquello que es producto de una selección, de un tratamiento y una publicitación (Sánchez-Noriega, 2002).

Interesante en este sentido es el estudio sobre los efectos desinformativos que van de la mano del profesional de la información y las carencias que se desprenden de estos (Galdón, 2006). Para el autor no es posible hacer periodismo sin hacer una revisión teórico-práctica sobre estos efectos y, en este sentido, plantea una serie de conceptos para el análisis. La obra responde a la pregunta de si estamos los ciudadanos bien informados y si es adecuado el tratamiento que se da a la información. Para ello, parte de la reflexión cultural-ideológica de los efectos desinformativos para adentrarse en el objetivismo como práctica periodística y terminar elaborando un concepto integrador de información periodística.

Por eso es necesario recordar que "las fuentes suministran información y responden preguntas, pero no hacen la información" (Casals, 2005). Los periodistas deben estar alerta para observar, para analizar, para valorar justamente" (López-Quintás, 2001). Ser periodista conlleva una cualidad innata que quizá pueda definirse sobre todo como veracidad. El lector debe estar convencido de que un autor determinado suele ser exacto, que tiene la genuina intención de reunir todos los datos significativos y que no va a jugar con ellos para obtener un efecto literario (Ash, 2000).

\section{Estado de la cuestión}

Los nuevos procesos comunicativos basados en la transmedialidad y remediación coordinada (Jenkins, 2006) han transformado la creación y la recepción de los contenidos. En este sentido, las investigaciones dan ejemplo de conocimiento distribuido generado y publicado por multitudes sociales que se coordinan de forma inteligente (Rheingold, 2004) para darse paso en la agenda informativa.

En este sentido, la finalidad de los cibermedios es la misma que la de los medios tradicionales: la producción informativa. Lo que ha cambiado es la forma en que se lleva a cabo esa producción (Barrios; Zambrano, 2015).

Los medios y la sociedad contemporánea están inmersos en una convergencia digital que se puede definir como el flujo de contenidos a través de múltiples plataformas (Jenkins 2008). Así, la cooperación entre diferentes industrias mediáticas y el comportamiento migratorio de las audiencias comparten el interés de impulsar contenidos en el medio digital que propicien nuevas experiencias de consumo.

Los usuarios prosumidores, aquellos que consumen y producen, han entrado en la escena mediática gracias a las nuevas tecnologías, como la realidad virtual o la rea- 
lidad aumentada, y al crecimiento exponencial de nuevos textos de la comunicación, como los videojuegos (Lotman, 1970). Tendencias como los Newsgames (Bogost; Ferrari; Schweiz, 2010), demandadas por los usuarios, validan la incorporación de desarrolladores de videojuegos en las redacciones, pues son un nuevo medio interactivo que representa nuevas formas de comunicación y abarcan un gran potencial de entretenimiento y educativo (De Kerckhove, 1997). Estas nuevas formas de comunicación han configurado nuevos escenarios donde conceptos tan relevantes como la gamificación y la simulación pueden ayudar en el proceso de la difusión de la información y el aprendizaje de las bases de la comunicación (Juul, 2001).

Sin embargo, esta nueva situación contextual (Chomsky, 1970), da lugar a una peculiaridad muy interesante, pues es el usuario el que libre y voluntariamente se introduce en el mundo informativo y, a través de su mirada, accede a un sinfín de mundos posibles (Albaladejo, 2001). La comunicación, por tanto, se ve afectada por la situación contextual de la persona que se informa y la situación, a su vez, afecta a la percepción de la información por parte del usuario que mira (Pearce, 2009). Lo digital es un nuevo mecanismo de interacción que funciona como una extensión del cuerpo material a través de un objeto inanimado (Juul, 2001) por el cual el usuario inicia un viaje personal, único y experiencial, que determina los contenidos que consume. Se construye una nueva forma de relación con el receptor (Scolari, 2013), que comienza a ser estudiado con profundidad, en tanto que es preciso conocer las reacciones de las nuevas generaciones ante formatos diferentes. Mediante diferentes capas de interpretación el usuario puede desdibujar las informaciones, reinterpretarlas, entenderlas desde marcos de referencia diversos, en el que cada uno de los usuarios evocará experiencias distintas a partir de un mismo contenido (Aarseth, 1997).

Es pues, una necesidad crear estudios que propicien un mejor entendimiento del medio (McLuhan, 1967) y ofrecer versiones de información que contrarresten la posverdad y la desinformación (Niño-González: 2017).

En su faceta de búsqueda, los usuarios multiplican las perspectivas de la información y los canales de acceso a la misma y, por ende, las tecnologías nos determinan (Carr, 2011). La información se convierte en un juego y el homo ludens (Huizinga, 1938), que muestra un buen desarrollo de sus habilidades tecnológicas, necesita competencias que le acompañen en el proceso de la comunicación y que le orienten sobre las nuevas tecnologías y formatos en que se le ofrece la información (Ryan, 2004). En este juego, el nuevo comunicador tiene la difícil tarea, en pos de la verdad y de la información, de hibridar nuevos formatos que hagan más eficaz conocer los relatos de la comunicación y ejecutar la complementariedad de la acción narrativa del todo basada en una estrategia combinada de los formatos (Torres-Negrín: 2017).

Por eso, se reclama la urgencia de adaptar el concepto de periodista a la nueva realidad del informador (Salaverría, 2016), a raíz del impacto de las nuevas tecnologías digitales en la generación de nuevos perfiles profesionales y, en su propia identidad.

A partir de estas consideraciones, las hipótesis de las que partimos en nuestra investigación son:

- La hibridación entre formatos tradicionales y nuevos formatos hace más eficaz el proceso de la comunicación entre las nuevas generaciones

- La aparición de nuevos formatos y formas de consumo deviene en un nuevo tipo de comunicador 
En ese sentido, los objetivos se pueden explicitar en:

1. Enfrentar a las nuevas generaciones a un relato periodístico desde diferentes narrativas: formato audiovisual y videojuegos

2. Descubrir las diferentes riquezas de los distintos formatos en el proceso de la comunicación

3. Estudiar la complementariedad de la acción narrativa combinada de ambos formatos

4. Estudiar las reacciones de las nuevas generaciones ante formatos diferentes

5. Validar la incorporación de desarrolladores de videojuegos en las redacciones

6. Desarrollar un estudio con metodología mixta mediante métodos cualitativos y cuantitativos en el campo del periodismo y los videojuegos

\section{Metodología}

\subsection{Muestra}

Este artículo se enmarca dentro en una investigación que hemos realizado en los grados en Periodismo y Creación y Narración de Videojuegos de la Facultad de Comunicación de la Universidad Francisco de Vitoria (Madrid) durante el curso 20172018 entre jóvenes universitarios.

La metodología empleada ha sido mixta puesto que al análisis cualitativo que se realizó mediante la aplicación y posterior reflexión de focus group se le añadió un análisis cuantitativo con la aplicación de un cuestionario y el análisis de los resultados.

El focus group se realizó antes de la aplicación del cuestionario pues sus resultados servirían como soporte para su mejor diseño.

EL desarrollo del focus group se efectuó como metodología de observación de una información que se proporciona desde fuera y permite posibilidades abiertas de análisis. El objetivo es buscar distintas formas de relación que hay dentro del tema, objeto de discusión (Galindo, 1998).

Se realizaron dos vueltas en los focus group para presentar a los participantes los dos formatos en momentos diferentes. En ambas vueltas se aplicó un guion de focus group. En la primera vuelta se preguntó lo siguiente:

a. ¿Qué narrativa te sugiere este formato?

b. ¿Qué elementos incorpora este formato que lo hacen único para comunicar con respecto a otros?

c. ¿Qué reacciones te sugiere este formato?

En la segunda vuelta, a estas tres preguntas se le añadieron dos:

d. ¿Cómo sería la narrativa ahora si combinases ambos formatos?

e. ¿Qué elementos has incorporado que antes no tenías? 
El cuestionario se realizó tras analizar los resultados de los dos focus group y se diseñó basándose en el desarrollo de competencias a través del aprendizaje, desplegado en estos formatos, unidos a las cuestiones sugeridas según objetivos. Por tanto, para su realización se requirió de:

1. Identificación de las competencias desarrolladas a través del aprendizaje de este formato.

2. Definición de comportamientos observables que permitan identificar al alumno al nivel de desarrollo de competencia que posee.

Se puede clasificar la muestra como no probabilística (Wimmer; Dominick, 1996) pues el objetivo era llegar a conclusiones a través de la recogida de datos más que generalizar los mismos.

Además, era del tipo accesible o de conveniencia e intencionada (Wimmer; Dominick, 1996) y por cuotas (Bigné; Miquel; Lévy; et, 1996) por tratarse de un grupo de fácil localización y accesibilidad y, al mismo tiempo, cumplir las características que se pedían para la eficacia de la investigación.

\subsection{Medidas}

Se eligió para realizar el trabajo de campo, la encuesta personal que favorecía obtener un mayor número de respuestas y plantear así las preguntas de la misma manera. Se optó por un tipo de cuestionario estructurado en el sentido de presentar a los entrevistados las preguntas estandarizadas y (Bigné; Miquel; Lévy; et, 1996). El objeto de la investigación exigía un tipo de cuestionario prácticamente cerrado que permitiera, posteriormente, medir en igualdad de condiciones todas las respuestas pues obligaría al entrevistado a escoger entre un conjunto de alternativas lo que permitiría una mejor medición del objeto perseguido (Bigné; Miquel; Lévy; et, 1996).

El inconveniente principal fue la posibilidad de que el entrevistado no optase por ninguna de las respuestas requeridas u optase por los dos formatos, lo que se subsanó añadiendo las opciones "ambos" y "ninguno" en la totalidad de las respuestas.

El cuestionario se realizó presencialmente en las clases de cada grupo por encuestadores previamente seleccionados para tal efecto, entre marzo y abril de 2018.

El objetivo del cuestionario era enfrentar a las nuevas generaciones a un relato periodístico desde diferentes narrativas: audiovisual y videojuegos y así descubrir las diferentes riquezas de los distintos formatos en el proceso de comunicación.

El cuestionario constaba de 19 ítems relativos a las preferencias que los jóvenes universitarios tienen de los diferentes formatos a la hora de informarse. Las opciones de respuesta eran diferentes en función de las preguntas emitidas. Las cuatro primeras preguntas correspondían a información relativa a la identificación de los encuestados y las dos últimas a versaban acerca de su participación en la actividad. Así, el cuestionario se centró en las 13 preguntas restantes.

Las preguntas eran de opción múltiple (Bigné; Miquel; Lévy; et, 1996) con el fin de obligar al entrevistado a escoger entre un conjunto de alternativas mutuamente excluyentes y exhaustivas tomadas de forma colectiva de donde deberían escoger la que mejor correspondiera a su respuesta. Por tanto, cada encuestado escogería una sola posibilidad de autoclasificación (Wimmer; Dominick, 1996). 
A continuación, detallamos el cuestionario:

\section{Cuestionario: Integración del videojuego y el audiovisual en el hecho informativo}

1: ¿Qué formato le permite emitir un juicio más cercano sobre el hecho informativo?
a. Videojuego
b. Audiovisual
c. Ambos
d. Ninguno

2: ¿Qué formato le ayuda más a interpretar el hecho informativo?
a. Videojuego
b. Audiovisual
c. Ambos
d. Ninguno

3: ¿Qué formato es susceptible de mejorar su narrativa?
a. Videojuego
b. Audiovisual
c. Ambos
d. Ninguno

4: ¿Qué formato le permite adquirir mejores competencias en comunicación?
a. Videojuego
b. Audiovisual
c. Ambos
d. Ninguno

5: ¿Qué formato le ha ayudado a interactuar mejor con el hecho informativo?
a. Videojuego
b. Audiovisual
c. Ambos
d. Ninguno

6: ¿Qué formato le ayuda a conocer mejor el contexto del hecho informativo?
a. Videojuego
b. Audiovisual
c. Ambos
d. Ninguno

7: ¿Qué formato le ha informado mejor?
a. Videojuego
b. Audiovisual
c. Ambos
d. Ninguno

8: ¿Qué formato le parece más realista?
a. Videojuego 

b. Audiovisual
c. Ambos
d. Ninguno

9: ¿Qué formato le parece más real?
a. Videojuego
b. Audiovisual
c. Ambos
d. Ninguno

10: ¿Qué formato le parece más humano?
a. Videojuego
b. Audiovisual
c. Ambos
d. Ninguno

11: ¿Qué formato le parece más impactante?
a. Videojuego
b. Audiovisual
c. Ambos
d. Ninguno

12: ¿Qué formato le parece más visual?
a. Videojuego
b. Audiovisual
c. Ambos
d. Ninguno

13: ¿Qué formato le parece más divertido?
a. Videojuego
b. Audiovisual
c. Ambos
d. Ninguno

\section{Resultados}

Tabla 1: Total cuestionarios

TOTAL

\begin{tabular}{|c|c|c|c|c|c|c|c|c|c|c|c|c|c|c|c|c|c|c|c|c|c|c|c|c|c|c|}
\hline & & 1 & 2 & 2 & & 3 & & 4 & & 5 & & 6 & & 7 & 8 & 8 & g & 9 & 10 & 0 & 11 & 1 & & 12 & & 13 \\
\hline & M & $\mathrm{H}$ & M & $\mathrm{H}$ & M & $\mathrm{H}$ & M & $\mathrm{H}$ & M & $\mathrm{H}$ & M & $\mathrm{H}$ & M & $\mathrm{H}$ & M & H & M & H & M & H & M & H & M & $\mathrm{H}$ & M & $\mathrm{H}$ \\
\hline Videojuego & $0 \%$ & $21 \%$ & $6 \%$ & $29 \%$ & $0 \%$ & $0 \%$ & $6 \%$ & $21 \%$ & $67 \%$ & $65 \%$ & $0 \%$ & $24 \%$ & $6 \%$ & $12 \%$ & $11 \%$ & $26 \%$ & $22 \%$ & $26 \%$ & $11 \%$ & $24 \%$ & $28 \%$ & $35 \%$ & $22 \%$ & $38 \%$ & $78 \%$ & $91 \%$ \\
\hline Audiovisual & $72 \%$ & $24 \%$ & $61 \%$ & $44 \%$ & $17 \%$ & $24 \%$ & $78 \%$ & $32 \%$ & $11 \%$ & $21 \%$ & $94 \%$ & $53 \%$ & $72 \%$ & $56 \%$ & $83 \%$ & $50 \%$ & $61 \%$ & $47 \%$ & $72 \%$ & $44 \%$ & $50 \%$ & $32 \%$ & $50 \%$ & $41 \%$ & $6 \%$ & $3 \%$ \\
\hline Ambos & $28 \%$ & $47 \%$ & $33 \%$ & $24 \%$ & $44 \%$ & $35 \%$ & $11 \%$ & $38 \%$ & $22 \%$ & $12 \%$ & $0 \%$ & $21 \%$ & $22 \%$ & $26 \%$ & $6 \%$ & $18 \%$ & $17 \%$ & $21 \%$ & $11 \%$ & $29 \%$ & $17 \%$ & $26 \%$ & $28 \%$ & $21 \%$ & $6 \%$ & $3 \%$ \\
\hline Ninguno & $0 \%$ & $0 \%$ & $0 \%$ & $0 \%$ & $0 \%$ & $0 \%$ & $0 \%$ & $0 \%$ & $0 \%$ & $3 \%$ & $6 \%$ & $3 \%$ & $0 \%$ & $6 \%$ & $0 \%$ & $6 \%$ & $0 \%$ & $6 \%$ & $6 \%$ & $3 \%$ & $6 \%$ & $6 \%$ & $0 \%$ & $0 \%$ & $0 \%$ & $0 \%$ \\
\hline
\end{tabular}

Elaboración propia. 
Según se muestra en la Tabla 1, de todos los ítems preguntados a la muestra, el formato audiovisual es el mejor valorado, con respecto al formato interactivo, en cuanto a la percepción de ser el más informativo. En su mayoría, consideran que el formato audiovisual es el que mejor les informa (ítem 7), el más humano (ítem 10) y el más realista (ítem 8). Por tanto, podemos resaltar el sostenimiento de la predilección por los formatos audiovisuales entre las nuevas generaciones para informarse.

Solo en dos apartados resulta el interactivo en una mejor posición como mejor formato para la comunicación: por ayudar a interactuar mejor con el hecho informativo (ítem 5) y por ser un formato más divertido, destacado por el 78\% de las mujeres y el $91 \%$ de los hombres (ítem 13).

Son reseñables también los ítems 11 y 9 por la división manifiesta de opiniones en cuanto a preferencia por uno de los formatos. El primero mide el impacto de los formatos, donde los entrevistados dividen su interés entre ambos formatos por igual. El segundo, mide cuál de los formatos ofrece una experiencia más real del hecho informativo, donde los totales muestran una diferencia de opinión con respecto al formato que les aporta esta cuestión.

Consideración aparte, resulta interesante también que, tras concluir su predilección por el formato audiovisual para la obtención de la información, el 72\% de las mujeres y el $82 \%$ de los hombres entienden que la combinación de ambos formatos facilita el conocimiento del hecho informativo. Así como el 94\% de las mujeres y el $85 \%$ de los hombres coinciden en que tras participar en la investigación han cambiado su idea sobre la comunicación.

Por sexos, también hallamos un porcentaje desigual en la valoración de los porcentajes.

El $72 \%$ de las mujeres considera que el formato audiovisual le ayuda a emitir un juicio más cercano sobre el hecho informativo, mientras que el $47 \%$ de los hombres se decanta por la combinación de ambos formatos, y otro $21 \%$ de los hombres por el interactivo.

Es apreciable en varios ítems la diferencia de percepción por sexos, por ejemplo, el ítem 6, donde las mujeres entienden por amplia mayoría que el audiovisual ayuda a conocer mejor el contexto del hecho informativo, mientras que casi la mitad de los hombres se decanta por el interactivo o el formato combinado.

Tabla 2: Resultados Grado en Periodismo

PERIODISMO

\begin{tabular}{|c|c|c|c|c|c|c|c|c|c|c|c|c|c|c|c|c|c|c|c|c|c|c|c|c|c|c|}
\hline & & 1 & & 2 & 3 & 3 & 4 & 4 & & 5 & & 6 & 7 & 7 & & 0 & & 9 & 1 & 0 & 1 & 11 & & 12 & 1 & \\
\hline & $M$ & $\mathrm{H}$ & $M$ & $\mathrm{H}$ & $M$ & $\mathrm{H}$ & M & $H$ & M & $\mathrm{H}$ & $M$ & $\mathrm{H}$ & $M$ & $\mathrm{H}$ & $M$ & $\mathrm{H}$ & M & $\mathrm{H}$ & $\mid \sqrt{|V|}$ & H & $M$ & $\mathrm{H}$ & $M$ & & $M$ & \\
\hline & $0 \%$ & $25 \%$ & $8 \%$ & & $0 \%$ & $0 \%$ & $0 \%$ & $8 \%$ & $69 \%$ & $75 \%$ & $0 \%$ & $25 \%$ & $8 \%$ & $17 \%$ & $15 \%$ & & $15 \%$ & & $0 \%$ & $17 \%$ & $15 \%$ & $17 \%$ & $23 \%$ & & & \\
\hline Audiovisual & $77 \%$ & $33 \%$ & $69 \%$ & $67 \%$ & $15 \%$ & $25 \%$ & $92 \%$ & $50 \%$ & $15 \%$ & $17 \%$ & $100 \%$ & $58 \%$ & $69 \%$ & $75 \%$ & $85 \%$ & $42 \%$ & $77 \%$ & $42 \%$ & $100 \%$ & $67 \%$ & $62 \%$ & $50 \%$ & $54 \%$ & $58 \%$ & $8 \%$ & $0 \%$ \\
\hline & $23 \%$ & $42 \%$ & $23 \%$ & $8 \%$ & $46 \%$ & $33 \%$ & $0 \%$ & $42 \%$ & $15 \%$ & $8 \%$ & $0 \%$ & $17 \%$ & $23 \%$ & $8 \%$ & $0 \%$ & $25 \%$ & $8 \%$ & $33 \%$ & $0 \%$ & $17 \%$ & $15 \%$ & $25 \%$ & $23 \%$ & $8 \%$ & $8 \%$ & $0 \%$ \\
\hline Ninguno & $0 \%$ & $0 \%$ & $0 \%$ & $0 \%$ & $0 \%$ & $0 \%$ & $0 \%$ & $0 \%$ & $0 \%$ & $0 \%$ & $0 \%$ & $0 \%$ & $0 \%$ & $0 \%$ & $0 \%$ & $0 \%$ & $0 \%$ & $0 \%$ & $0 \%$ & $0 \%$ & $8 \%$ & $8 \%$ & $0 \%$ & $0 \%$ & $0 \%$ & $0 \%$ \\
\hline
\end{tabular}

Elaboración propia.

En el Grado en Periodismo, la muestra destaca mayoritariamente los ítems 2, 3, $4,6,7$ y 8 , en lo que se refiere a aquellos aspectos relacionados con la mejor comunicación del hecho informativo pues facilitan la interpretación, la comprensión, el contexto y el ofrecimiento de una información más realista. No obstante, valoran, como muestran los totales, la capacidad del interactivo por su interacción con el 
usuario y por ser este formato más entretenido y ser de gran impacto por su carácter innovador (ítems 5, 11 y 13).

Tabla 3: Resultados Grado en Creación y Narración de Videojuegos

\begin{tabular}{|c|c|c|c|c|c|c|c|c|c|c|c|c|c|c|c|c|c|c|c|c|c|c|c|c|c|c|}
\hline \multicolumn{27}{|c|}{ VIDEOUJEGOS } \\
\hline \multicolumn{27}{|c|}{ VIUEUJUEGUS } \\
\hline & M & $\mathrm{H}$ & M & $\mathrm{H}$ & M & H & M & H & M & H & M & H & M & $\mathrm{H}$ & M & H & M & $\mathrm{H}$ & M & $\mathrm{H}$ & M & $\mathrm{H}$ & M & $\mathrm{H}$ & & $\mathrm{H}$ \\
\hline Videojuego & $0 \%$ & $18 \%$ & $0 \%$ & $32 \%$ & $0 \%$ & $0 \%$ & $17 \%$ & $27 \%$ & $60 \%$ & $659 \%$ & $0 \%$ & $23 \%$ & $0 \%$ & $9 \%$ & $0 \%$ & $23 \%$ & $40 \%$ & $27 \%$ & $40 \%$ & $27 \%$ & $60 \%$ & $45 \%$ & $20 \%$ & $41 \%$ & $80 \%$ & $80 \%$ \\
\hline Audiovisual & $60 \%$ & $18 \%$ & $40 \%$ & $32 \%$ & $20 \%$ & $23 \%$ & $33 \%$ & $23 \%$ & $0 \%$ & $23 \%$ & $80 \%$ & $50 \%$ & $80 \%$ & $45 \%$ & $80 \%$ & $55 \%$ & $20 \%$ & $50 \%$ & $0 \%$ & $32 \%$ & $20 \%$ & $23 \%$ & $40 \%$ & $32 \%$ & $0 \%$ & $5 \%$ \\
\hline Ambos & $40 \%$ & $50 \%$ & $60 \%$ & $32 \%$ & $40 \%$ & $36 \%$ & $33 \%$ & $36 \%$ & $40 \%$ & $14 \%$ & $0 \%$ & $23 \%$ & $20 \%$ & $36 \%$ & $20 \%$ & $14 \%$ & $40 \%$ & $14 \%$ & $40 \%$ & $36 \%$ & $20 \%$ & $27 \%$ & $40 \%$ & $27 \%$ & $0 \%$ & $5 \%$ \\
\hline Ninguno & $0 \%$ & $0 \%$ & $0 \%$ & $0 \%$ & $0 \%$ & $0 \%$ & $0 \%$ & $0 \%$ & $0 \%$ & $5 \%$ & $20 \%$ & $5 \%$ & $0 \%$ & $9 \%$ & $0 \%$ & $9 \%$ & $0 \%$ & $9 \%$ & $20 \%$ & $5 \%$ & $0 \%$ & $5 \%$ & $0 \%$ & $0 \%$ & $0 \%$ & $0 \%$ \\
\hline
\end{tabular}

Elaboración propia.

En el Grado en Creación y Narración de Videojuegos, por su parte, los alumnos coinciden con sus compañeros del Grado en Periodismo en el valor del audiovisual en cuanto a que aporta una mejor narrativa para informar y ofrecer un contexto realista y humano del hecho (ítems $3,6,7,8$ y 10). No obstante, la diferencia aumenta considerablemente en cuanto a la mejor apreciación del formato cuando se refieren a aspectos importantes para ellos como la interacción, la diversión y el impacto (ítems 5 , 11 y 13). La información audiovisual es para este grupo más realista, pero el formato interactivo ofrece una experiencia más real (ítem 9). Asimismo, este grupo aprecia en mayor medida que en el Grado en Periodismo haber cambiado su idea de la comunicación tras la investigación.

\section{Conclusiones}

La bibliografía académica utilizada en este trabajo cuestiona el concepto de verdad informativa. La consideración de que la audiencia es permanentemente adoctrinada supone la necesidad de poner especial énfasis a la hora de ofrecer una información rigurosa (Kovach; Rosenstiel, 2003).

Así, el concepto de desinformación tiende a ser sustituido por el de verdad informativa (Blázquez, 2002). Por eso es necesaria una revisión en profundidad, tanto del concepto de información como del papel que le corresponde al profesional de la información (Galdón, 2006).

En este sentido, es necesario replantearse las herramientas a disposición del periodista que sirvan para un mayor conocimiento del hecho informativo y asegure, como se contempla en nuestro artículo 20 de la Constitución Española, el derecho de todo ciudadano a recibir una información veraz.

Queda demostrado que el concepto de medio de comunicación incluye tanto a los medios tradicionales como a los cibermedios (Barrios; Zambrano, 2015), donde el proceso de comunicación queda afectado por la interacción producida en la recepción del mensaje.

Por lo tanto, es necesaria la colaboración y la integración de los agentes que intervienen en el proceso de la comunicación haciendo especial hincapié en los canales a través de los cuales se transmite el mensaje, entendidos estos en un sentido muy amplio pues a las aportaciones habituales de los medios tradicionales (imagen, 
sonido, etc.), ahora se le añaden las bondades de los nuevos medios en cuanto a interactividad, transmedialidad, gamificación, instantaneidad, etc (Jenkins, 2008).

Por otro lado, ya es un hecho que la audiencia está en un proceso de transformación que le está convirtiendo en prosumidor y demanda sin límites una nueva manera de participación en la agenda informativa. Esto ha supuesto una forma nueva relación del receptor con los contenidos, donde el lector exige corroborar en primera persona el hecho informativo (Scolari, 2013).

Asimismo, es cada vez más urgente adaptar el perfil del periodista a las nuevas tecnologías, pues el impacto de lo digital en su formación requiere nuevos perfiles profesionales (Salaverría, 2016).

Parece razonable, por tanto, que en este nuevo escenario el concepto de verdad se vea cuestionado y se reclame desde la profesión periodística una reflexión en profundidad que supere el concepto de posverdad en aras construir una sociedad más orientada al bien (García-Noblejas, 2000).

Los objetivos marcados en este trabajo de investigación se orientan en esta línea. Como conclusión nuestro trabajo muestra la necesidad de enfrentar a las nuevas generaciones de periodistas a diferentes narrativas para alcanzar un mejor conocimiento del hecho informativo y satisfacer las exigentes demandas de los nuevos lectores. No obstante, como se aprecia en los resultados, las nuevas generaciones, si bien aprecian los nuevos formatos, siguen mostrando una preferencia por los lenguajes más tradicionales y conocidos.

A pesar de esto valoran los diferentes elementos que ambos formatos aportan, especialmente el potencial de entretenimiento de los canales más interactivos.

Esto nos lleva a resaltar la necesaria complementariedad de ambos formatos en lo que se refiere a la acción narrativa. En este sentido, tenemos que destacar las posibilidades de futuro que vislumbramos. Los resultados nos hacen pensar que es necesario seguir experimentando con los nuevos formatos en el campo de la comunicación.

La combinación de nuevos formatos nos sugiere un escenario con amplio potencial creativo para las futuras generaciones en el campo de la comunicación. Por eso son necesarias acciones formativas que ayuden a enriquecer la comunicación del hecho informativo, como la introducción de desarrolladores de videojuegos en las redacciones, para no correr el peligro de caer en la desinformación que puede provocar la posverdad impulsada por las masas.

\section{Referencias bibliográficas}

Aaarseth, E. (1997). Cybertext. Perspectives on Ergodic Literature. Baltimore: The John Hopkins University Press.

Albaladejo, T. (2001). Retórica, tecnologías, receptores [Rhetoric, technology, audiences]. Revista de Retórica y Teoría de la Comunicación, año I, núm. 1. Retrieved from http:// www3.ubu.es/blogubuabierta/wp-content/uploads/2014/07/T.Albaladejo.-Ret\%C3\%B3rica-tecnologias-receptores.pdf

Barrios, A.; Zambrano, W. R. (2015). Convergencia Digital: Nuevos perfiles profesionales del periodista [Digital converge: new media profiles]. Anagramas; Universidad de Medellín. V. 13, n. 26. Retrieved from http://revistas.udem.edu.co/index.php/anagramas/article/view/1190 
Blázquez, N. (2000). El desafio ético de la información [Ethic's challeges in media]. Salamanca: Edibesa. ISBN: 9788484071143

Bogost, I.; Ferrari, S.; Schweiz, B. (2010). Newsgames: Journalism at Play. Massachussets Institute of Technology: The Mit Press.

Carr, N. (2011). Superficiales: Qué está haciendo internet con nuestras mentes [What is doing Internet with our minds]. Madrid: Taurus.

Casals Carro, M. J. (2005). Periodismo y sentido de la realidad. Teoría y análisis de la narrativa periodística [Journalism and reality sense. Media narrative theory and analyse]. Madrid: Fragua. ISBN: 8470741705

Chomsky, N. (1965): Aspectos de la teoría de la sintaxis [Aspects Of The Theory Of Sintax]. Madrid: Aguilar.

De Kerckhove, D. (1997). Inteligencias en Conexión [Connected Intelligence]. Barcelona: Gedisa.

Galdón López, G. (2006). Desinformación. Método, aspectos y soluciones [Desinformation. Method, aspects and solutions]. Pamplona: EUNSA. ISBN: 9788431324186

Galindo Cáceres, J. (1998). Técnicas de investigación en sociedad, cultura y comunicación [Research techniques in society, culture and communication]. México: Addison Wesley Longman. ISBN: 968-444-262-9

García-Noblejas Liniers, J. J. (2000). Comunicación borrosa. Sentido práctico del periodismo y de la ficción cinematográfica [Diffuse communication. Practical Journalism sense and cinema 's fiction]. Pamplona: España: EUNSA. ISBN: 84-313-1774-4

Huizinga, J. (1938). Homo ludens. Buenos Aires: Emecé.

Jenkins, H. (2006). Convergence Culture: Where Old and New Media Collide. New York: New York University Press.

Juul, J. (2001). Games Telling stories? A brief note on games and narratives. Game Studies, v. 1, n. 1. Retrieved from http://www.gamestudies.org/0101/juul-gts/

Kovach, B.; Rosenstiel, T. (2012). Los elementos del periodismo [Journalism clues]. Madrid, España: Aguilar. ISBN: 9788403012394

López Quintás, A. (2001). La tolerancia y la manipulación [Tolerance and manipulation]. Madrid: Rialp. ISBN: 9788432133336

Lotman, Y. (1970) La estructura del texto artístico [Artistic structure text]. Akal Itsmo.

McLuhan, M. (1967). The Medium is the Massage. Random House. 2000.

Miquel, S.; Bigné, E.; Lévy, J. P.; Cuenca, A. C. y Miquel, M. J. (1996). Investigación de mercados [Markets research]. Madrid: Mc Graw-Hill. ISBN: 9788448107383

Muñoz-Torres, J. R. (2000). Concepciones epistemológicas implícitas en los libros de estilo de El País, El Mundo y ABC [Epistemologic concept in style book at El País, El Mundo y ABC]. ZER, v.5, n.9. Retrieved from http://www.ehu.eus/ojs/index.php/Zer/article/ view/17438/15211

Niño-González, J. I. (2017). Opinión Pública e Intoxicación en las redes: los fundamentos de la postverdad [Public opinión and internet toxicity: postruth theory]. Revista de Comunicación Vivar Academia. n. 139. Retrieved from http://www.vivatacademia.net/index.php/ vivat/article/view/1083/1294 doi.org/10.15178/va.2017.139.83-94

Pearce, C. (2009). "Identity-as-Place: Fictive Ethnicities in Online Games \& Virtual Worlds”. Comparative media studies. Retrieved from https://cmsw.mit.edu/celia-pearce-identity-as-place/

Ramonet, I. (2003). La tiranía de la comunicación [Communication tirany]. Madrid: Debate. ISBN: 9788483065419 
Rheingold, H. (2009). Multitudes inteligentes: la próxima revolución social [Smart Mobs: the Next Social Revolution]. Barcelona: Gedisa.

Ryan, M. L. (2004). La narración como realidad virtual [Narrative as Virtual Reality]. Barcelona: Ediciones Paidós Ibérica.

Salaverría, R. (2016). Redefinir al comunicador [Redefining the journalists]. El Profesional de la Información, v.25, n.2. Retrieved from http://dx.doi.org/10.3145/epi.2016.mar.02

Sánchez Noriega, J. L. (2002). Historia del cine: Teoría y géneros cinematográficos, fotografía y televisión [Movie History: theory and genders, fotography and televisión]. Madrid: Alianza Editorial. ISBN: 9788420657929

Scolari, C. (2013). Narrativas transmedia [Transmedia narrative]. Barcelona: Deusto.

Torres-Negrín, E. (2017). Las narraciones digitales interactivas como recurso didáctico gamificado en Educación Superior [ Digital narrative as teaching gamification resources at School]. En V Congreso Internacional de Videojuegos y Educación (CIVE'17). Retrieved from https://riull.ull.es/xmlui/handle/915/6789?show=full

Vázquez, J. M. (1990). Manipulación, información [Manipulation, information]. Madrid: Instituto de Sociología Aplicada. ISBN: 84-86111-08-0

Wimmer, R. D. y Dominick, J. R. (1996). La investigación cientifica de los medios de comunicación [Cientific research in media], $1^{\text {a }}$ Edición, Traducción de José Luis Dader. Barcelona: Bosch Casa Editorial. ISBN: 84-7676-359-X 